\title{
sciendo
}

DOI 10.2478/sbe-2020-0007

SBE no. 15(1) 2020

\section{ENTERPRISE RISK MANAGEMENT PRACTICES AND SURVIVAL OF SMALL AND MEDIUM SCALE ENTERPRISES IN NIGERIA}

\author{
IBIWOYE ADE \\ University of Lagos, Nigeria \\ MOJEKWU JOSEPH \\ University of Lagos, Nigeria \\ DANSU FRANCIS \\ Lagos State University, Nigeria
}

\begin{abstract}
:
The survival rate of Small and Medium Scale Enterprises (SMEs) have been found to be low despite all the effort made by the government to sustain their existence. This seems to be linked to the poor management of various risk factors confronting the operators of the sector in Nigeria. In view of this, the study is aimed at determining the influence of Enterprise Risk Management (ERM) practices on survival of SMEs in Lagos State. With the application of cross-sectional survey technique, a sample of 400 operators was selected among SMEs across Lagos State. Data which were generated through structured questionnaires were analysed using both descriptive and inferential statistical tools. Results indicate that ERM practices significantly influence the survival of SMEs in Lagos State. Based on the findings, it was recommended that SMEs owners should take ERM practices as a valuable business function that enhances survival. Also, government should continue to sensitise SMEs on the benefits of ERM and put in place mandatory ERM guidelines to compel SMEs to practice it.
\end{abstract}

Key words: Enterprise risk management, small and medium scale enterprises, survival

\section{Introduction}

Small and Medium Scale Enterprises (SMEs) contribute significantly to the socioeconomic growth and development of many countries. The roles of SMEs is reflected in their capability to create employment, alleviate poverty, equitably distribute income and resources, enhance innovation, develop entrepreneurial skills, encourage urbanisation and 
improve the living standard of the people (Aigboduwa \& Oisamoje, 2013). In Nigeria, the significance of the contribution of SMEs is evidenced in the survey conducted by the Small and Medium Enterprises Development Agency of Nigeria (SMEDAN, 2013) in which it was revealed that there are over 37 million SMEs in Nigeria, employing $84.02 \%$ of the total workforce, and contributing $48.5 \%$ and $7.3 \%$ to the country's Gross Domestic Product (GDP) and exports respectively.

Notwithstanding the immense roles performed by SMEs in the economy and their perceived huge potentials, contribution of the sector towards sustainable economic development, appears to be relatively low. As reported by Oba and Onuoha (2013), SMEs' contribution to aggregate industrial output and capacity utilisation in Nigeria is as low as $15 \%$ and $30 \%$ respectively. The reason for this low performance appears to be the low survival rate of SMEs common to most low income countries. In Nigeria, most SMEs do not survive their first five years of establishment. Specifically, $80 \%$ to $85 \%$ of them fail before their fifth anniversary while another $10 \%$ to $15 \%$ die before reaching 10 years (Eniola, Entenbang \& Sakariyau, 2015; Agwu \& Emeti, 2014). The factors militating against the survival of SMEs seem to be embedded in the various risks hindering small businesses from growing and performing their various economic functions. This challenge is further aggravated by the poor approach of SMEs to the practice of Enterprise Risk Management (ERM).

ERM is developed to address the perceived inadequacies of the Traditional Risk Management (TRM). Before the advent of ERM, risk management is practiced in an isolated manner such that risks are not handled centrally in an organisation. More importantly is the fact that not all types of risks are considered within the framework of TRM. Razali and Tahir (2011) opined that ERM is a systematic discipline and integrated method directed at managing organisational risks in order to create and maximize value for stakeholders. The principle of ERM supports a holistic approach where strategic, financial, hazard, operational and other organisational risks are combined and addressed simultaneously. Furthermore, it helps to identify potential events capable of affecting the enterprise and manage them to ensure that they fall within the organisation's risk appetite.

ERM Framework by the Committee of Sponsoring Organisations of the Treadway Commission (COSO, 2004) is adopted by this study. Togok, Isa and Zainuddin (2014) in their study had engaged this framework to operationalise ERM effectiveness. The framework comprises of eight interrelated functions through which organisations can effectively manage their risks to facilitate survival. These include Internal Environment, Objective Setting, Event Identification, Risk Assessment, Risk Response, Control Activities, Information \& Communication, and Monitoring.

A surviving organisation is one with the capacity to continue to acquire inputs from suppliers and utilise it to generate output required by a set of consumers (Sheppard, 1993). Survival has been used in the literature to mean different things. It is often used interchangeably with other variables including performance, growth or success. In this study, survival is conceptualised to mean non-failure of an existing SMEs within the first five years of creation. The moment a firm can no longer takes delivery of inputs due to its inability to pay for previous supplies, survival of such a firm is uncertain. 
Previous attempts captured the different determining variables for SMEs' survival under various classifications (Lampadarios, 2016; Raguz, Colovic \& Beran, 2015; Ng \& Kee, 2012). This study adopts the most common categorisations of the determinants of firm survival. Survival is hereby measured using the following three dimensions of Entrepreneurial Characteristics (managerial experience, entrepreneurial skills, risk taking propensity, need for achievement and family influence); Enterprise Characteristics (access to finance, availability of relevant and skilled employees, smooth succession plan, maintenance of appropriate business and financial records and productivity) and Environmental Characteristics (competition, supports of government agencies, compliance with legal requirements, availability of basic infrastructure and modern technology).

The main purpose of this study is to determine the influence of Enterprise Risk Management (ERM) practices on the survival of SMEs in Lagos State, Nigeria. It aims at examining the contribution of each of the components of ERM to survival of SMEs in Lagos State. The outcome of the study will reveal the potentials of ERM implementation in reducing the failure rate of small enterprises in Lagos State. To achieve this objective, the study hypothesises that ERM practices have no significant influence on the survival of SMEs in Lagos State.

\section{Review of Relevant Literature}

The rate of risk management adoption among SMEs appears to be low. This is in spite of the increase in awareness of its inherent potentials (Verbano \& Venturi, 2013). Cormican (2014) had found that organisations do not priotise risk management and therefore recommended the adoption of ERM as an integrated approach to managing organisational risks. The outcomes of several researches in the past have indicated that the implementation of ERM or risk management in general by SMEs will enhance the achievement of set objectives (Agrawal, 2016).

The practice of ERM by SMEs in South Africa seems to be low. This is reflected in a study by Masama, et al., (2012) aimed at investigating the contributions of ERM to the success of SMEs. Based on quantitative analysis, the outcome of the study showed that majority of South African SMEs informally engaged in ERM activities. This finding is similar to the result of another study in the context of Zimbabwe. The study carried out by Gwangwava, Manuere, Kudakwashe, Tough and Rangarirai (2014) utilised primary data in an exploratory and descriptive study to examine the extent of risk management implementation among SMEs. The results indicated that most SMEs do not practice risk management. Additionally, the study found that there is a $50 \%$ chance that an increase in risk management spending will enhance performance. The findings of Olowokudejo and Nwankwo (2016) in their qualitative study among Nigerian SMEs to investigate the contribution of risk management to SMEs performance seem to align with the above findings. This study revealed that though SMEs regard risk management practice as fundamental to business operations, most of them lack systematic risk management approach. However, a study in the Malaysian context performed by Yap and Yap (2016) to examine the rate of ERM adoption and its effects on sales among SMEs based on primary 
data showed that most SMEs in Malaysia practice ERM. The study further emphasised the importance of ERM by showing that ERM practice will enhance SMEs sustainability.

Agrawal (2016) mentioned that SMEs will benefit immensely from a good implementation of ERM programme through transforming risks into opportunities, engaging in favourable competition, creation of value, enhancing safety and achievement of sustainable development. Kehinde, Opeyemi, Benjamin, Adedayo and Abel (2017) found out that there is a significant positive relationship between the practice of ERM and the survival of SMEs in Nigeria. Adeyele and Omorokunwa (2017) found that a direct and positive relationship exist between effective risk financing and probability of SMEs' survival. In the Canadian non-financial sector, Quon, Zeghal and Maingot (2012) studied the relationship between ERM and firm performance by using data obtained from annual reports of the $2007 / 2008$ and $2008 / 2009$ business years and established that no significant relationship exist between ERM implementation and firm performance.

The ability of ERM practices to enhance financial performance was subjected to empirical investigation in Cameroon. The study was performed by Mamai and Yinghua (2017) and the results show that the relationship between risk culture and financial performance is significant and positive but there is an inverse relationship between board independence and financial performance. The study also found that risk management practice and devolution of powers between management and ownership jointly have significant negative effect on performance. In another study, Madembu, Namusonge and Sakwa (2017) found that risk management contributes significantly to SMEs' financial performance. However, the research indicated that most SMEs failed to consider risk management practice as a key element of business management.

ERM has the potential of contributing to the performance of financial institutions. This is revealed by a study in Nigerian context by Idris and Norlida (2016). The results evidenced that a significant and positive relationship exist between ERM practice and organisational profitability, customer satisfaction and ability to take relevant decisions. A similar study by Pagach and Warr (2010) revealed that the contribution of ERM practices to the various performance variables is limited and insignificant.

The conceptual model proposed for this study as illustrated by figure 1 below describes an interaction between two variables. ERM practices and survival of SMEs. The eight components of the COSO ERM framework are hereby adopted as indicators for the ERM practices. The variable for measuring business survival varies as indicated by the approaches of previous studies. Selected indicators of the three dimensions including enterprise, entrepreneur and environmental characteristics are considered as proxies for SMEs survival. 


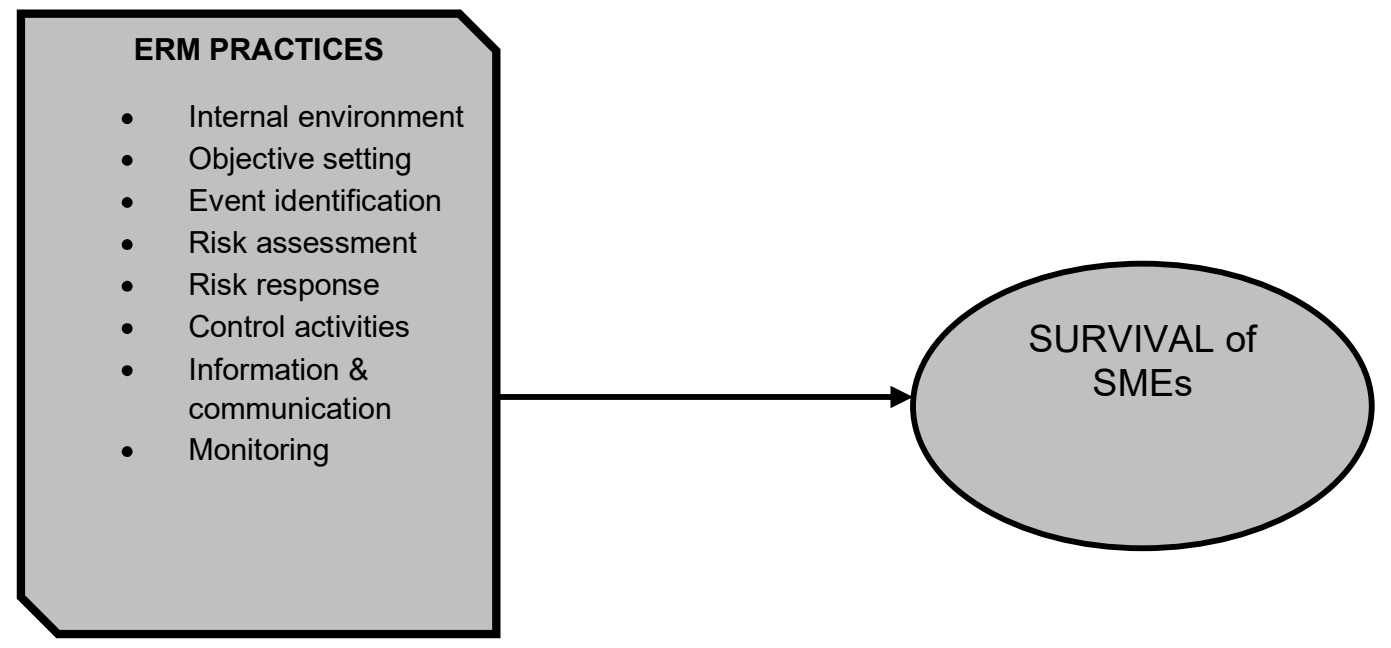

Figure 1: Conceptual Model

Source: Adapted by the Researcher, (2017)

\section{Methodology}

The study is descriptive in nature since it attempts to explain the contribution of ERM practices to the survival of SMEs. It is cross-sectional and it engages the survey strategy to generate the required primary data. The population of the study include all SMEs that have being operating for at least five uninterrupted years since their establishment in Lagos State. About 11, 663 SMEs operate in Lagos State according to SMEDAN (2013). This figure was adopted as the population of the study.

The sample size for this study is 400 SMEs determined using the Yamane (1967) formula as provided by Singh and Masuku (2014). The multi-stage sampling technique was mainly adopted to select the sample. Stratified random sampling technique was engaged in the first stage, to select three of the registered associations of SMEs in Lagos State, taking each of them as existing stratum. In the second stage, quota sampling technique was employed to proportionally allocate the sample size to the three selected SMEs' associations. This was carried out in consideration of the membership strength of each of the association. In view of this, 179 SMEs were selected from the Association of Small Business Owners of Nigeria (ASBON), 151 SMEs were selected from the Nigerian Association of Small Scale Industrialists (NASSI) and 70 SMEs were selected from the Nigerian Association of Small and Medium Enterprises (NASME). Thirdly, these numbers of SMEs were conveniently selected from among the members of the associations on their meeting days. Convenience sampling technique was adopted because some of the SME owners were not willing to participate in the study.

Data were obtained from owners/managers of selected SMEs who were taken as the subjects of the study. Structured questionnaires administered to the owners/managers of 400 SMEs selected in Lagos State were used to generate primary data for the study. Various sections of the questionnaire were adapted from the scales used by previous researchers (Sefiani, 2013; Togok, Isa \& Zainuddin, 2014; Lekhanya, 2016). However, as 
counseled by Kothari and Garg (2016), the new questionnaire was subjected to a pilot study. The questionnaire was divided into three sections. Section A of the questionnaire sought information relating to demographic variables. This section comprised 14 items. Items relating to the practice of ERM were covered in section $\mathrm{B}$. This section was adapted from Togok, Isa and Zainuddin (2014) with a reliability value of 0.992 . It contained 24 items developed from the eight components of the COSO ERM framework. Three questions were developed from each of the ERM component. Section $C$ which was titled Survival of SMEs was adapted from Sefiani (2013) with reliability values between 0.63 and 0.97 and Lekhanya (2016) having 0.68 reliability value. It comprised of 15 items covering the three dimensions of business survival including enterprise, entrepreneur and environmental characteristics. Five items were raised from each dimension.

Copies of the questionnaires were administered by the researchers with supports from three research assistants. A total of 400 questionnaires were administered out of which 313 copies were collected and found useful for the study. The data were analysed with the aid of Statistical Package for Social Sciences data editor (SPSS) software, version 20. Forward Stepwise Multiple Regression Analysis was used to determine the influence of each of the various components of ERM practice to survival of SMEs.

\section{Data Presentation, Analysis and Interpretation}

ERM practices do not significantly influence the survival of SMEs in Lagos State.

$$
\text { Survival of SMEs }=\alpha_{11}+\beta_{11} \text { ERM practices }+\mu_{1} \quad \ldots \text { (1a) }
$$

Where:

Independent variable $=$ Enterprise Risk Management practices $=($ ERM practices $)$

Dependent Variable $=$ Survival of SMEs

$\alpha_{11}=$ Intercept on the $y$ axis

$\beta_{11}=$ Coefficient of $X$. (the mean change in the $Y$ variable for every 1-unit increase in $X$ variable).

$\mu_{1}=$ error term.

Table 4.1: Model Summary for Hypothesis One

\begin{tabular}{|l|l|}
\hline R Square & 0.151 \\
\hline$F$ & 21.611 \\
\hline Sig. & 0.000 \\
\hline$\alpha_{1}$ & 3.186 \\
\hline$\beta_{1(\text { ERM })}$ & 0.265 \\
\hline
\end{tabular}

Source: Author's Computation, 2017

$$
S=3.186+0.265 \text { ERM }
$$

The model summary on table 4.1 shows that there is a positive relationship between ERM practices and survival of SMEs in Lagos State. The coefficient of determination designated by $R^{2}$ which is equal to 0.151 shows that $15.1 \%$ of the survival rate of SMEs in Lagos State could be explained by the current level of ERM practice of the SMEs owners. This result is statistically significant because the p-value $(0.000)$ of the 
generated result is less than the level of significance (0.05) used for the study. An evaluation of the unstandardized coefficient of ERM practice in the coefficient table and its associated $p$-value shows that ERM Practice ( $\beta_{1}$ ERM $=0.265, p<0.05$ ) is statistically significant and can be used to predict the survival of SMEs in Lagos State. The simple regression equation model $S=3.186+0.265$ ERM signifies that a unit change in ERM practice will increase the survival of SMEs in Lagos State by $26.5 \%$.

\subsection{Contribution of ERM Practices' Components to Survival of SMEs using Forward Stepwise Multiple Regression Analysis.}

The eight components of ERM practices engaged in this study are Event Identification (EI), Risk Assessment (RA), Risk Response (RR), Control Activities (CA), Information and Communication (IC), Monitoring (MN), Internal Environment (IE) and Objective Setting (OS).

$S=\alpha_{21}+\beta_{21} I E+\beta_{22} R A+\beta_{23} R R+\beta_{24} C A+\beta_{25} I C+\beta_{26} \mathrm{MN}+\beta_{27} I E+\beta_{28} \mathrm{OS}+\mu_{2}$

Where:

Independent variable $=$ Enterprise Risk Management practices $=(E R M)$

Dependent Variable $=$ Survival of SMEs $=(S)$

$\alpha_{21}=$ Intercept on the $y$ axis

$\beta_{21} \ldots \beta_{28}=$ Coefficient of Event Identification (EI), Risk Assessment (RA), Risk Response (RR), Control Activities (CA), Information and Communication (IC), Monitoring (MN), Internal Environment (IE) and Objective Setting (OS).

$S=$ Survival of SMEs

$\mu_{2}=$ error term.

Table 4.2: Model Summary for Contributions of ERM Practices' Components to Survival of SMEs

\begin{tabular}{|c|c|c|c|c|}
\hline Model & $\mathrm{R}$ & $\mathrm{R}$ Square & $\begin{array}{c}\text { Adjusted R } \\
\text { Square }\end{array}$ & $\begin{array}{c}\text { Std. Error of the } \\
\text { Estimate }\end{array}$ \\
\hline 1 & $.810^{\mathrm{a}}$ & .657 & .655 & .31291 \\
2 & $.961^{\mathrm{b}}$ & .924 & .923 & .14808 \\
3 & $.968^{\mathrm{c}}$ & .937 & .936 & .13476 \\
4 & $.983^{\mathrm{d}}$ & .965 & .965 & .09987 \\
5 & $.985^{\mathrm{e}}$ & .970 & .970 & .09296 \\
6 & $.986^{\mathrm{f}}$ & .972 & .971 & .09025 \\
7 & $.986^{\mathrm{g}}$ & .973 & .972 & .08946 \\
\hline
\end{tabular}

a. Predictors: (Constant), IE

b. Predictors: (Constant), IE, RA

c. Predictors: (Constant), IE, RA, CA

d. Predictors: (Constant), IE, RA, CA, MN

e. Predictors: (Constant), IE, RA, CA, MN, EI

f. Predictors: (Constant), IE, RA, CA, MN, EI, RR

g. Predictors: (Constant), IE, RA, CA, MN, EI, RR, IC

Source: Author's Computation, 2017 
Table 4.2 shows the variance in survival of SMEs when each of the selected variables is entered. It shows that 0.657 of the variance in survival of SMEs is explained by internal environment when the other components of ERM practices are kept constant. This indicates that only internal environment account for $65.7 \%$ of the success recorded in survival of SMEs in Lagos State. With the addition of risk assessment to the model, the variance observed in survival of SMEs increased to 0.924 . This implies that $92.4 \%$ of the success recorded in survival of SMEs in Lagos State is accounted for by internal environment and risk assessment. When control activities is added to the model, the variance observed in survival further increased to 0.937 . This means that $93.7 \%$ of the success recorded in survival of SMEs is jointly accounted for by internal environment, risk assessment and control activities.

The addition of monitoring to the regression model increased the variance observed in survival of SMEs to 0.965 , signifying that $96.5 \%$ of the success recorded in survival of SMEs in Lagos State is accounted for jointly by internal environment, risk assessment, control activities and monitoring. In the next stage when event identification was included in the model, the variance observed in survival of SMEs was increased to 0.970. This implies that $97 \%$ of the success recorded in survival of SMEs is jointly accounted for by internal environment, risk assessment, control activities, monitoring and event identification. The addition of risk response to the regression model also increased the variance observed in survival of SMEs to 0.972 . This suggests that $97.2 \%$ of the success recorded in survival of SMEs is accounted for by a combination of internal environment, risk assessment, control activities, monitoring, event identification and risk response. Finally, the addition of information and communication to the model increased the variance observed in survival of SMEs to 0.973 . This signifies that $97.3 \%$ of the success recorded in survival of SMEs in Lagos State is jointly accounted for by internal environment, risk assessment, control activities, monitoring, event identification, risk response and information \& communication.

Table 4.3: Contributions of ERM Practices' Components to Survival of SMEs

\begin{tabular}{|c|c|c|c|c|c|c|}
\hline \multirow{2}{*}{\multicolumn{2}{|c|}{ Model }} & \multicolumn{2}{|c|}{$\begin{array}{l}\text { Unstandardized } \\
\text { Coefficients }\end{array}$} & \multirow{3}{*}{$\begin{array}{l}\text { Standardized } \\
\text { Coefficients } \\
\text { Beta } \\
\end{array}$} & \multirow{3}{*}{$\begin{array}{l}\mathrm{T} \\
18.898\end{array}$} & \multirow{3}{*}{$\begin{array}{l}\text { Sig. } \\
.000\end{array}$} \\
\hline & & \multirow{2}{*}{$\begin{array}{l}\mathrm{B} \\
.941\end{array}$} & \multirow{2}{*}{$\begin{array}{l}\text { Std. Error } \\
.050\end{array}$} & & & \\
\hline 1 & (Constant) & & & & & \\
\hline & IE & .482 & .020 & .810 & 24.384 & .000 \\
\hline \multirow{3}{*}{2} & (Constant) & .149 & .034 & & 4.437 & .000 \\
\hline & IE & .431 & .010 & .724 & 44.337 & .000 \\
\hline & RA & .196 & .013 & .288 & 15.490 & .000 \\
\hline \multirow{4}{*}{3} & (Constant) & .160 & .031 & & 5.218 & .000 \\
\hline & $\mathrm{IE}$ & .377 & .011 & .633 & 34.022 & .000 \\
\hline & $\mathrm{RA}$ & .142 & .013 & .209 & 10.651 & .000 \\
\hline & $\mathrm{CA}$ & .116 & .014 & .170 & 8.069 & .000 \\
\hline \multirow{2}{*}{4} & (Constant) & -.031 & .026 & & -1.207 & .228 \\
\hline & IE & .151 & .016 & .254 & 9.232 & .000 \\
\hline
\end{tabular}


Studies in Business and Economics no. 15(1)/2020

\begin{tabular}{|c|c|c|c|c|c|c|}
\hline & RA & .145 & .010 & .213 & 14.672 & .000 \\
\hline & CA & .319 & .017 & .467 & 19.202 & .000 \\
\hline & $\overline{M N}$ & .329 & .021 & .396 & 15.932 & .000 \\
\hline \multirow{6}{*}{5} & (Constant) & -.088 & .025 & & -3.493 & .001 \\
\hline & $\mathrm{IE}$ & .156 & .015 & .263 & 10.237 & .000 \\
\hline & RA & .138 & .009 & .203 & 14.951 & .000 \\
\hline & $\mathrm{CA}$ & .351 & .016 & .513 & 21.752 & .000 \\
\hline & $\mathrm{MN}$ & .311 & .019 & .375 & 16.047 & .000 \\
\hline & El & .167 & .024 & .190 & 6.953 & .000 \\
\hline \multirow{7}{*}{6} & (Constant) & -.052 & .026 & & -2.021 & .044 \\
\hline & IE & .126 & .016 & .212 & 7.743 & .000 \\
\hline & RA & .139 & .009 & .205 & 15.510 & .000 \\
\hline & $\mathrm{CA}$ & .389 & .018 & .568 & 21.782 & .000 \\
\hline & $\mathrm{MN}$ & .357 & .021 & .430 & 16.613 & .000 \\
\hline & El & .132 & .025 & .150 & 5.343 & .000 \\
\hline & RR & -.050 & .011 & -.057 & -4.431 & .000 \\
\hline \multirow{8}{*}{7} & (Constant) & -.093 & .030 & & -3.070 & .002 \\
\hline & IE & .130 & .016 & .218 & 8.003 & .000 \\
\hline & RA & .134 & .009 & .197 & 14.712 & .000 \\
\hline & $\mathrm{CA}$ & .384 & .018 & .562 & 21.640 & .000 \\
\hline & MN & .359 & .021 & .432 & 16.841 & .000 \\
\hline & $\mathrm{El}$ & .166 & .028 & .189 & 5.939 & .000 \\
\hline & $\mathrm{RR}$ & -.059 & .012 & -.067 & -5.016 & .000 \\
\hline & IC & .028 & .011 & .038 & 2.525 & .012 \\
\hline
\end{tabular}

Source: Author's Computation, 2017

Table 4.3 shows the Forward Stepwise Multiple Regression analysis of the components of ERM practices on the Survival of SMEs in Lagos State. Specifically, it includes the individual components at each stage of the modelling. These are described as follows:

a. Internal Environment

$$
S=0.941+0.482 \mathrm{IE}
$$

An evaluation of the unstandardized coefficient of internal environment in the coefficient table and its associated $p$-value shows that internal environment $\left(\beta_{\mathrm{IE}}=0.482, p\right.$ $<0.05)$ is statistically significant and can be used to predict the survival of SMEs. The simple regression equation model $S=0.941+0.482 \mathrm{IE}$ signifies that a unit change in internal environment by SMEs in Lagos State will enhance their survival rate by $48.2 \%$.

b. Internal Environment and Risk Assessment

$$
S=0.149+0.431 \mathrm{IE}+0.196 \mathrm{RA}
$$

An evaluation of the unstandardized coefficient of internal environment and risk assessment in the coefficient table and their associated $p$-values show that internal environment $\left(\beta_{\mathrm{IE}}=0.431, p<0.05\right)$ and risk assessment $\left(\beta_{\mathrm{RA}}=0.196, p<0.05\right)$ are statistically significant and can be used to predict the survival of SMEs in Lagos State. With the inclusion of internal environment and risk assessment, the regression equation model $S=0.149+0.431 \mathrm{IE}+0.196 \mathrm{RA}$ implies that a unit change in internal environment 
by SMEs in Lagos State will enhance their survival rate by $43.1 \%$ and a unit change in risk assessment by SMEs in Lagos State will increase their survival rate by $19.6 \%$.

c. Internal Environment, Risk Assessment and Control Activities

$$
S=0.160+0.377 \mathrm{IE}+0.142 \mathrm{RA}+0.116 \mathrm{CA}
$$

An evaluation of the unstandardized coefficient of internal environment, risk assessment and control activities in the coefficient table and their associated $p$-values show that internal environment $\left(\beta_{\mathrm{IE}}=0.377, p<0.05\right)$, risk assessment $\left(\beta_{\mathrm{RA}}=0.142, p<\right.$ 0.05 ) and control activities $\left(\beta \mathrm{CA}_{\mathrm{A}}=0.116, p<0.05\right.$ )are statistically significant and can be used to predict the survival of SMEs in Lagos State. With the inclusion of internal environment, risk assessment and control activities, the regression equation model $\mathrm{S}=$ $0.160+0.377 \mathrm{IE}+0.142 \mathrm{RA}+0.116 \mathrm{CA}$ implies that a unit change in internal environment by SMEs in Lagos State will enhance their survival rate by $37.7 \%$; a unit change in risk assessment by SMEs in Lagos State will increase their survival rate by $14.2 \%$; while for every unit change in control activities, survival of SMEs in Lagos State will increase by $11.6 \%$.

d. Internal Environment, Risk Assessment, Control Activities and Monitoring

$$
S=-0.031+0.151 I E+0.145 R A+0.319 C A+0.329 M N
$$

An evaluation of the unstandardized coefficient of internal environment ,risk assessment, control activities and monitoring in the coefficient table and their associated $p$-values show that internal environment $\left(\beta_{\mathrm{IE}}=0.151, p<0.05\right)$, risk assessment $\left(\beta_{\mathrm{RA}}=\right.$ $0.145, p<0.05)$, control activities, $\left(\beta_{C A}=0.319, p<0.05\right)$ and monitoring $\left(\beta_{M N}=0.329, p<\right.$ 0.05 )are statistically significant and can be used to predict the survival of SMEs in Lagos State. With the inclusion of internal environment, risk assessment, control activities and monitoring, the regression equation $S=-0.031+0.151 \mathrm{IE}+0.145 \mathrm{RA}+0.319 \mathrm{CA}+$ 0.329MN implies that a unit change in internal environment by SMEs in Lagos State will enhance their survival rate by $15.1 \%$; a unit change in risk assessment by SMEs in Lagos State will increase their survival rate by $14.5 \%$; a unit change in control activities, survival of SMEs in Lagos State will increase by $31.9 \%$; while for every unit change in monitoring, survival of SMEs in Lagos State will increase by $32.9 \%$.

e. Internal Environment, Risk Assessment, Control Activities, Monitoring and Event Identification

$$
S=-0.088+0.156 \mathrm{IE}+0.138 \mathrm{RA}+0.351 \mathrm{CA}+0.311 \mathrm{MN}+0.167 \mathrm{EI}
$$

An evaluation of the unstandardized coefficient of internal environment, risk assessment, control activities, monitoring and event identification in the coefficient table and their associated $p$-values show that internal environment $\left(\beta_{\mathrm{IE}}=0.156, p<0.05\right)$, risk assessment $\left(\beta_{R A}=0.138, p<0.05\right)$, control activities, $\left(\beta_{C_{A}}=0.351, p<0.05\right)$, monitoring $(\beta \mathrm{MN}=0.311, p<0.05)$ and event identification $(\beta \mathrm{El}=0.167, p<0.05$ )are statistically significant and can be used to predict the survival of SMEs in Lagos State. With the inclusion of internal environment, risk assessment, control activities, monitoring and event identification, the regression equation $S=-0.088+0.156 \mathrm{IE}+0.138 \mathrm{RA}+0.351 \mathrm{CA}+$ $0.311 \mathrm{MN}+0.167 \mathrm{El}$ implies that a unit change in internal environment by SMEs in Lagos State will enhance their survival rate by $15.6 \%$; a unit change in risk assessment by SMEs in Lagos State will increase their survival rate by $13.8 \%$; with a unit change in control 
activities, survival of SMEs in Lagos State will increase by $35.1 \%$; for every unit change in monitoring, survival of SMEs in Lagos State will increase by $31.1 \%$; while for every unit change in event identification, survival of SMEs in Lagos State will increase by $16.7 \%$.

f. Internal Environment, Risk Assessment, Control Activities, Monitoring, Event Identification and Risk Response

$$
S=-0.052+0.126 \mathrm{IE}+0.139 \mathrm{RA}+0.389 \mathrm{CA}+0.357 \mathrm{MN}+0.132 \mathrm{EI}-0.050 \mathrm{RR}
$$

An evaluation of the unstandardized coefficient of internal environment, risk assessment, control activities, monitoring, event identification and risk response in the coefficient table and their associated $p$-values show that internal environment $\left(\beta_{\mathrm{IE}}=0.126\right.$, $p<0.05)$, risk assessment $(\beta R A=0.139, p<0.05)$, control activities, $\left(\beta C_{A}=0.389, p<\right.$ 0.05 ), monitoring $(\beta \mathrm{MN}=0.357, p<0.05)$, event identification $(\beta \mathrm{El}=0.132, p<0.05)$, and risk response $(\beta R R=0.050, p<0.05$ )are statistically significant and can be used to predict the survival of SMEs in Lagos State. With the inclusion of internal environment, risk assessment, control activities, monitoring, event identification and risk response, the regression equation $S=-0.052+0.126 \mathrm{IE}+0.139 \mathrm{RA}+0.389 \mathrm{CA}+0.357 \mathrm{MN}+0.132 \mathrm{EI}-$ $0.050 \mathrm{RR}$ implies that a unit change in internal environment by SMEs in Lagos State will enhance their survival rate by $12.6 \%$; a unit change in risk assessment by SMEs in Lagos State will increase their survival rate by $13.9 \%$; with a unit change in control activities, survival of SMEs in Lagos State will increase by $38.9 \%$; for every unit change in monitoring, survival of SMEs in Lagos State will increase by $35.7 \%$; for every unit change in event identification, survival of SMEs in Lagos State will increase by $13.2 \%$; while for every unit change in risk response, survival of SMEs in Lagos State will decrease by $5.0 \%$.

g. Internal Environment, Risk Assessment, Control Activities, Monitoring, Event Identification, Risk Response and Information \& Communication

$$
\begin{gathered}
S=-0.093+0.130 \mathrm{IE}+0.134 \mathrm{RA}+0.384 \mathrm{CA}+0.359 \mathrm{MN}+0.166 \mathrm{EI}-0.059 \mathrm{RR}+ \\
0.028 \mathrm{IC}
\end{gathered}
$$

An evaluation of the unstandardized coefficient of internal environment, risk assessment, control activities, monitoring, event identification, risk response and information \&communication in the coefficient table and their associated p-values show that internal environment $\left(\beta_{\mathrm{IE}}=0.130, p<0.05\right)$, risk assessment $\left(\beta_{\mathrm{RA}}=0.134, p<0.05\right)$, control activities, $\left(\beta_{C A}=0.384, p<0.05\right)$, monitoring $(\beta \mathrm{mN}=0.359, p<0.05)$, event identification $\left(\beta_{E I}=0.166, p<0.05\right)$, risk response $\left(\beta_{R R}=0.059, p<0.05\right)$ and information \&communication $(\beta \mathrm{IC}=0.028, p<0.05$ )are statistically significant and can be used to predict the survival of SMEs in Lagos State. With the inclusion of internal environment, risk assessment, control activities, monitoring, event identification, risk response and information \&communication, the regression equation $S=-0.093+0.130 \mathrm{IE}+0.134 \mathrm{RA}$ $+0.384 \mathrm{CA}+0.359 \mathrm{MN}+0.166 \mathrm{EI}-0.059 \mathrm{RR}+0.028 \mathrm{IC}$ implies that a unit change in internal environment by SMEs in Lagos State will enhance their survival rate by $13.0 \%$; a unit change in risk assessment by SMEs in Lagos State will increase their survival rate by 13.4\%; with a unit change in control activities, survival of SMEs in Lagos State will increase by $38.4 \%$; for every unit change in monitoring, survival of SMEs in Lagos State will increase by $35.9 \%$; for every unit change in event identification, survival of SMEs in Lagos State will increase by $16.6 \%$; but for every unit change in risk response, survival of 
SMEs in Lagos State will decrease by $5.9 \%$; while for every unit change in information \&communication, survival of SMEs in Lagos State will increase by $2.8 \%$.

\section{Discussion of Results}

The results of the regression analysis confirmed that ERM implementation will positively and significantly influence the survival of SMEs in Lagos State. The results specifically show that ERM practice contribute only about $26.5 \%$ to the survival of SMEs in Lagos State. This seems to be because SMEs in Lagos State passively implement ERM as confirmed by the findings of earlier studies in Nigeria (lopev \& Kwanum, 2012; Olowokudejo \& Nwankwo, 2016). The low rate of ERM practice by SMEs is not exclusive to Nigerian context. Related findings were also obtained from empirical investigations in South Africa (Masama, et al., 2012); Zimbabwe (Gwangwava, et al., 2014); Kenya (Madembu, Namusonge \& Sakwa, 2017).

The results further revealed that out of the eight components of ERM, internal environment exerts the highest influence on the survival of SMEs in Lagos State. Risk Assessment function is considered next to internal environment. This is followed by Control Activities and then Monitoring. The analysis also found Event Identification to positively contribute to survival. Lastly, sharing of Information and communication among organisational members appears to have significant influence on survival of SMEs in Lagos State. The contribution of risk response to survival is negative. This indicates that SMEs in Lagos State lack the skills needed to select and apply the appropriate treatment techniques for the risks identified. It was found that though SMEs do apply risk treatment techniques, they mostly select the wrong treatment devices.

This finding corroborates the results of a number of related researches in the past. One of such is the findings of Kehinde, et al., (2017) which found that the practice of ERM is positively and significantly related with the survival of SMEs in Nigeria. The results equally support the findings of another study in Nigerian context by Adeyele and Omorokunwa (2017) which reported a direct and positive relationship between effective risk financing and probability of SMEs to survive. Furthermore the outcome of the present study seems not to contend with the findings of Idris and Norlida (2016) which found the existence of a significant and positive relationship between ERM practices and organisational profitability, customer satisfaction and ability to take relevant decisions. The findings also conform to the outcome of similar researches carried out in other economies. Among such is a Malaysian based study by Yap and Yap (2016) which established that ERM practices will effectively enhance the sustainability of SMEs.

The results of the statistical analysis contradict the findings of some previous empirical researches. Specifically, it is inconsistent with the findings of Pagach and Warr (2010) in their USA based study which revealed a limited and insignificant contribution of ERM practices to the performance of publicly listed companies having Chief Risk Officer (CRO). Similarly, the findings contradict the outcome of a Canadian research by Quon, Zeghal and Maingot (2012) which established that no significant relationship exists between ERM implementation and firm performance. A recent study in the Cameroonian perspective by Mamai and Yinghua (2017) to examine the relationship between ERM 
practices and financial performance also show an opposing result to the current study. The result is equally in conflict with the findings by Chikomba, Dube and Tsekea (2013) which state that most Zimbabwean SMEs are still unable to fulfil their financial obligations despite putting risk management programme in place.

\section{Conclusion and Implications}

The only way by which SMEs can fulfil their purpose for both their proprietors and the economy at large is when they are able survive through the various stages of the organisational life circle and by extension succeed their founder. This study views that with the practice of Enterprise Risk Management (ERM); SMEs will be able to address the risks hindering their survival and hence be positioned to achieve set objectives. ERM is an essential organisational function by which risks are addressed holistically within the enterprise so as to minimise negative impacts, and to identify and exploits possible opportunities in order to give maximum value to all stakeholders. ERM has proven to be an important strategy for achieving organisational success. The findings of this study appear to have affirmed this. In view of the findings, the researchers hereby identify the following managerial and policy implications:

i. There is need for SMEs in Lagos State and entrepreneurs generally to recognise and consider ERM as an important business function that will not only help them to achieve effective risk management but will equally enhance their survival.

ii. The government through SMEDAN and other relevant agencies and stakeholders should embark on different kinds of sensitisation campaigns with the aim of educating SMEs on the benefits of ERM and mode of practicing it.

iii. The government, through relevant agencies should consider the certification of SMEs' owners, managers and staff in the area of ERM practice in other to increase the level of awareness and practice of ERM by SMEs.

iv. As it is in the financial sector, a mandatory ERM guideline is recommended for the SMEs sector. This will compel SMEs across all sectors to take their risk management function seriously.

\section{References}

Adeyele, J. S. \& Omorokunwa, O. G. (2017). Risk appetites and empirical survival pattern of small and medium enterprises in Nigeria. The Journal of Entrepreneurial Finance, 18(2), 1-22.

Agrawal, R. (2016). 'Enterprise risk management' essential for survival and sustainable development of micro, small and medium enterprises. International Review, No1-2, 117-124. Retrieved from http://www.scindeks-clanci.ceon.rs

Agwu, M. O. \& Emeti, C. I. (2014). Issues, challenges and prospects of small and medium scale enterprises (SMEs) in Port-Hacourt city, Nigeria. European Journal of Sustainable Development, 3(1), 101-114. Doi: 10.14207/ejsd.2014.v.3n1p101.

Aigboduwa, J. E. \& Oisamoje, M. D. (2013). Promoting small and medium enterprises in Nigerian oil and gas industry. European Scientific Journal, 9(1), 244-261.

Cormican, K. (2014). Integrated enterprise risk management: From process to best practice. Modern Economy, 5, 401-413. doi.org/10.4236/me.2014.54039. 
Eniola, A. A., Entenbang, H. \& Sakariyau, O. B. (2015). Small and medium scale business performance in Nigeria: Challenges faced from an intellectual capital perspective. International Journal of Research Studies in Management, 4(1), 59-71. DOI: 10.5861/ijrsm.2015.964.

Gwangwava, E., Manuere, F., Kudakwashe, G., Tough, C. \& Rangarirai, F. (2014). An assessment of risk management practices in SMEs in Zimbabwe: A review and synthesis. IOSR Journal of Humanities and Social Sciences, 19(8), 6-14.

Idris, A. \& Norlida, A. M. (2016). Influence of enterprise risk management framework implementation and board equity ownership on firm performance in Nigerian financial sector: An initial finding. IOSR Journal of Business and Management, 18(1), 61-68. DOI: 10.9790/487X-18126168.

lopev, L. \& Kwanum, I. M. (2012). An assessment of risk management of small and medium scale enterprises in Nigeria. Research Journal of Finance and Accounting, 3(5), 151-158.

Kehinde, A., Opeyemi, A., Benjamin, A. Adedayo, O. \& Abel, O. A. (2017). Enterprise risk management and the survival of small scale businesses in Nigeria. International Journal of Accounting Research, 5(2), 2-8. DOI: 10.4172/2472-114X.1000165.

Kothari, C. R. \& Garg, G. (2016). Research methodology: Methods and techniques. New Delhi, India: New Age International (P) Limited Publishers.

Lampadarios, E. (2016). Critical success factors for SMEs: An empirical study in the UK chemical distribution industry. International Journal of Business and Management, 11(7), 67-82. DOI: 10.5539/ijbm.v11n7p67.

Lekhanya, L. M. (2016). Business characteristics of small and medium enterprises in rural areas: A case study on southern region of KwaZulu-Natal province of South Africa. Problems and Perspectives in Management, 14(3), 108-114. Doi:10.21511/ppm.14(3).2016.11.

Madembu, A. W., Namusonge, G. \& Sakwa (2017). The role of risk management on financial performance of small and medium enterprises in Kenya. International Journal of Science and Research, 6(1), 2125-2130. DOI: 10.21275/ART20164543.

Mamai, M. \& Yinghua, S. (2017). Enterprise risk management best practices for improvement financial performance in manufacturing SMEs in Cameroon. International Journal of Management Excellence, 8(3), 1004-1012.

Masama, B. T., Ndlovu, E., Mambwe, T., Rabohome, C., Chakabva, O., Fologang, B., ... \& Bruwer, J. P. (2012). Enterprise risk management: A managing partner for business success. African Journal of Business Management, 6(48), 11782-11786. DOI: 10.5897/AJBM12.1159.

$\mathrm{Ng}, \mathrm{H}$. S. \& Kee, D. M. H. (2012). The issues and development of critical success factors for SME success in a developing country. International Business Management, 6(6), 680-691.

Oba, U. O. \& Onuoha, B. C. (2013). The role of small and medium scale enterprises in poverty reduction in Nigeria: 2001 - 2011. African Research Review, 7(4), 1-25. DOI: http://dx.doi.org/10.4314/afrev.7i4.1

Olowokudejo, F. F. \& Nwankwo, S. I. (2016). Business risk management and organisational performance: Empirical evidence from small and medium enterprises (SMEs) in Nigeria. Journal of Economics and Management, 1, 32-41.

Pagach, J. \& Warr, R. (2010). The effects of enterprise risk management on firm performance. Available at SSRN: https://www.papers.ssrn.com or http://dx.doi.org/10.2139/ssrn.1155218

Quon, T. K., Zeghal, D. \& Maingot, M. (2012). Enterprise risk management and firm performance. Procedia - Social and Behavioural Sciences, 62, 263-267. DOI: 10.1016/j.sbspro.2012.09.042.

Raguz, I. V., Colovic, Z. K. \& Beran, I. M. (2015). The analysis of business performance in small and medium hospitality enterprises in the republic of Croatia. Zbornik Sveucilista u Dubrovniku, 2, 85-98. Retrieved from https://www.hrcak.srce.hr 


\section{Studies in Business and Economics no. 15(1)/2020}

Razali, A. R. \& Tahir, I. M. (2011). Review of the literature on enterprise risk management. Business Management Dynamics, 1 (5), 8-16.

Sefiani, Y. (2013). Factors for success in SMEs: A perspective from Tangier. Unpublished Ph.D. Thesis, Faculty of Business, Education and Professional Studies, University of Gloucestershire, UK. Retrieved from http://www.eprints.glos.ac.uk

Sheppard, J. P. (1993). Organisational survival and corporate level diversification. The Journal of Financial and Strategic Decisions. Retrieved from http://www.sfu.ca

Singh, A. S. \& Masuku, M. B. (2014). Sampling techniques \& determination of sample size in applied statistics research: An overview. International Journal of Economics, Commerce and Management, 2(11), 1-17.

Small and Medium Enterprises Development Agency of Nigeria (SMEDAN) (2013). SMEDAN and National Bureau of Statistics collaborative survey: Selected findings. Retrieved from http://www.nigerianstat.gov.ng

Togok, S., Isa, C. R. \& Zainuddin, S. (2014). Operationalising enterprise risk management (ERM) effectiveness. Journal of Accounting Perspectives, 7, 28-48.

Verbano, C. \& Venturini, K. (2013). Managing risks in SMEs: A literature review and research agenda. Journal of Technology Management \& Innovation, 8(3), 186-197.

Yap, K. H. A. \& Yap, S. T. (2016). Enterprise risk management: Evidence from small-medium enterprises. Malaysian Accounting Review, 15(2), 151-170. 